\title{
OPEN Visibility and attractiveness of Fritillaria (Liliaceae) flowers to potential pollinators
}

\author{
Katarzyna Roguz ${ }^{1 凶}$, Laurence Hill², Sebastian Koethe ${ }^{3}$, Klaus Lunau ${ }^{3}$, Agata Roguz ${ }^{4}$ \& \\ Marcin Zych ${ }^{1}$
}

Visual floral characters play an important role in shaping plant-pollinator interactions. The genus Fritillaria L. (Liliaceae), comprising approximately 140 species, is described as displaying a remarkable variety of flower colours and sizes. Despite this variation in visual floral traits of fritillaries, little is known about the potential role of these features in shaping plant-pollinator interactions. Here, we seek to clarify the role of visual attraction in species offering a robust food reward for pollinators early in the spring, which is the case for Fritillaria. We also searched for potential tendencies in the evolution of floral traits crucial for plant-pollinator communication. The generality of species with green and purple flowers may indicate an influence of environmental factors other than pollinators. The flowers of the studied species seem to be visible but not very visually attractive to potential pollinators. The food rewards are hidden within the nodding perianth, and both traits are conserved among fritillaries. Additionally, visual floral traits are not good predictors of nectar properties. When in the flowers, pollinators are navigated by nectar guides in the form of contrasting nectary area colouration. Flower colour does not serve as a phenotypic filter against illegitimate pollinators-red and orange birdpollinated fritillaries are visible to bees.

Visual floral traits are key features that define plants' interactions with the surrounding environment. As a result, flowers show extreme variation in visual traits, even among closely related taxa ${ }^{1}$. The factors driving this divergence remain an open area of research. The observed diversity of visual floral traits, e.g., colour, size, the arrangement of reproductive parts and reward properties, has largely been attributed to selection mediated by pollinator preferences $^{2-5}$. Among these flower traits, colour plays a crucial role in shaping plant-animal interactions ${ }^{6}$. Numerous studies have shown that flower colour often reflects pollinators' preferences ${ }^{7-10}$ and plant species pollinated by similar animal groups often share similar colour properties ${ }^{11}$. For instance, in the case of North American Penstemon Schmidel species, colour is the best predictor of flower visitation by hummingbirds ${ }^{12,13}$, and in insect-pollinated Mimulus L. species, bees responded primarily to tepal colour ${ }^{14}$. The extensive flower divergence may occur because members of different pollinator groups may perceive flowers differently ${ }^{15-17}$ due to variation in their colour vision systems, including the presence or absence of ultraviolet and red light sensitivity.

Attractiveness to potential pollinators is not the only factor shaping flower colour. The risk of losing floral food rewards produced by plants results in selection pressure on flower colour to discourage less effective flower visitors or flower thieves ${ }^{16}$. The most cited examples include 'anti-bee' features of hummingbird-pollinated flowers $^{18,19}$, which are described as reflecting mostly long-wavelength light. These traits may decrease their visibility to bees and other illegitimate visitors, helping protect the rewards for legitimate polliatators ${ }^{7}$.

Floral pigments, responsible for flower colour, also play an important role in plant physiology. Therefore, several plant lineages show little or no association between flower colour and pollination mode ${ }^{20}$. In some species, flower colour may be explained by phylogenetic constraints, pleiotropic effects, adaptations against herbivores, pathogens or local habitat condition ${ }^{21,22}$. Flavonoids, for example, are involved in the plant response to stress caused, e.g., by drought ${ }^{1}$, or protect plants against damage caused by UV radiation ${ }^{23}$.

Similarly to flower colour, flower size is closely linked to pollinator attraction. Larger flowers are more easily detected ${ }^{24}$ and offer more rewards, such as pollen and nectar ${ }^{25}$. As a result, several studies have documented pollinator-mediated phenotypic selection for larger flowers ${ }^{26}$. On the other hand, there are several factors selecting for smaller flowers ${ }^{24}$. Overall, biotic factors other than pollinators (e.g., herbivores), together with abiotic

${ }^{1}$ Botanic Garden, Faculty of Biology, University of Warsaw, Warsaw, Poland. ${ }^{2}$ Petersham Lodge, Richmond, UK. ${ }^{3}$ Institute of Sensory Ecology, Faculty of Biology, Heinrich-Heine-Universität Düsseldorf, Düsseldorf, Germany. ${ }^{4}$ National Information Processing Institute, Al. Niepodległości 188 B, 00-608 Warszawa, Poland. ${ }^{\square}$ email: k.roguz@biol.uw.edu.pl 
factors (e.g., resource availability and climate), can exert selection for smaller flowers. Theory predicts that smaller flowers may be advantageous, especially in terms of water balance, but only when pollinators are abundant and efficient ${ }^{24}$.

Both of these traits, flower colour and size, in addition to being involved in attraction and protection, may also be a signal informing potential pollinators about the properties of the available reward ${ }^{27,28}$. Nectar and pollen are the most common food rewards offered to pollinators. Of these, nectar is perhaps the most important ${ }^{29,30}$, playing a key role in plant reproduction by rewarding floral visitors ${ }^{29}$. Nectar properties, such as concentration and volume, can determine plant-pollinator interactions ${ }^{27,31}$. Pollinators preferentially visit flowers richer in rewards, which they assess based on visual floral traits ${ }^{32,33}$. Recent studies have also shown the potential role of presenting the reward itself ${ }^{34}$, with pollen or nectar shaping flower attractiveness ${ }^{35}$. The presentation of yellow anthers has been shown to positively affect visitation as well as pollen receipt and pollen removal from flowers ${ }^{36}$. The arrangement of reproductive parts, however, may announce the available rewards but should also "guide" pollinator movements within the flower. Thus, floral traits such as corolla entrance diameter or floral designs likely also evolved to enable and increase the effectiveness of pollination.

Despite the available studies, our understanding of how flowers evolve and adapt to the surrounding environment remains fragmentary. One of the tools used to address questions related to flower evolution is the theory of pollination syndromes ${ }^{37}$. The fundamental assumption of this concept is that flowers adapt to their most efficient functional pollinator group (most efficient in terms of removing and depositing pollen, Dellinger ${ }^{38}$ and literature cited therein). A recent analysis of Dellinger ${ }^{38}$ showed that one can predict pollinators based on flower colour; however, other traits, such as the reward and perianth width, are more reliable. Nevertheless, since numerous plant species are pollinated by multiple functional groups of animals, questions about the influence of such multi-pollinator systems remain open. Furthermore, flower colour shifts, which may result from a single gene mutation, can also lead to a change in other floral traits, such as flower size or reward properties ${ }^{39}$.

To better understand the role of visual floral traits, we studied colour properties and visual signalling in flowers of the temperate spring flowering genus Fritillaria (Liliaceae). The choice was based on the variation in visual floral traits and pollination biology and ecology $\mathrm{y}^{40-42}$. The genus Fritillaria comprises approximately 140 species of bulbous plants dispersed predominantly in temperate Holarctic regions of both the Old and New Worlds ${ }^{43-45}$, with the highest diversity observed in the Mediterranean region ${ }^{46-51}$. Flowers of fritillaries are generally nodding, with a tulip-like trimerous perianth concealing nectaries and stamens, usually shorter than the tepals. Several representatives of this genus have unusual tessellation on the tepals formed from a repeating bi-coloured chequered pattern. Despite many similarities, fritillaries differ, e.g., in terms of size and colour (for human vision). The most recent common ancestor, for example, probably had purple flowers, and this colour is the most common among modern species. There was, however, one transition to red flowers and one to orange flowers ${ }^{52}$. We still do not fully understand this divergence in fritillaries, but it may be related to pollination systems, at least to some extent. Flower features of most of the fritillaries indicate pollination by insects, but there have been at least two shifts from insect to bird pollination. Orange Asian F. imperialis is pollinated by passerines ${ }^{53,54}$, and red American F. gentneri and F. recurva are pollinated by hummingbirds ${ }^{55}$. Additionally, the properties of nectar reflect the preferences of their bird pollinators, with hummingbird-pollinated species producing very large amounts of nectar with medium sugar concentrations and passerine bird-pollinated species producing very large amounts of highly diluted nectar ${ }^{38,41}$. Additionally, among insect-pollinated fritillaries, there are possible shifts in the main pollinators. Fritillaria camtschatcensis is pollinated by flies ${ }^{56}$, and this species has distinct floral traits and reward properties ${ }^{40,41}$ compared to those of species, e.g., bee-pollinated fritillaries.

Since previous studies have shown that fritillaries offer a robust food reward to pollinators, we wanted to study the visual properties of fritillary flowers and the potential correlation between floral traits and reward properties. How attractive are Fritillaria flowers to potential pollinators, and are there any floral guides in the ultraviolet spectrum? Can flower size, i.e., entrance diameter and tepal length, play a role in potential advertisement of the nectar reward? To assess the attractiveness of fritillaries, we determined the areas of the tepals, which are conspicuous to pollinators and thus function as a visual attractant. Subsequently, we measured the spectral reflectance of the inner and outer surfaces of the tepals. Searching for potential nectar guides on the tepals, we measured the reflectance of the nectaries. Additionally, to find out more about the way bee pollinators perceive Fritillaria flowers, we prepared false-colour pictures. Finally, we tracked the evolution and assessed the ancestral states of flower features, which may be crucial in shaping plant-pollinator interactions.

\section{Materials and methods}

Spectral analysis. Most Fritillaria species are rare in nature and grow in hardly accessible, remote places. Therefore, performing studies in natural habitats on a satisfying number of species is often not possible. Nonetheless, to gain better insight into plant-pollinator communication in fritillaries, we decided to use material available at the University of Warsaw Botanic Garden (hereafter BG) and in private collections. For this analysis, we used flowers from plants cultivated in the BG and in private collections of Colin Everett (Somerton, Somerset, UK; hereafter CE), Laurence Hill (Richmond, Surrey, UK; hereafter LH) and Paweł Kalinowski (Szczeglacin, Korczew, Poland; hereafter PK). One species (F. messanensis) was analysed in situ on Crete. Since most of the Fritillaria species are also rare in cultivation, the number of flowers analysed varied due to the availability of plant material (the sources and sample sizes used in this study are listed in Supplementary materials Table 1).

To better understand the visual attractiveness of Fritillaria flowers, we performed spectral reflectance analyses of 35 species (Fig. 1, Supplementary materials Table 1). Since there are few species of fritillaries with red flowers (with the exception of F. eastwoodiae, where the red tepals have a large amount of yellow admixed in) and all of them are bird-pollinated (Supplementary materials Fig. 1), we wanted to test the eventual deterrence of insect visitors by these red flowers, which was previously detected in studies of bird-pollinated species ${ }^{57}$. Flowers from 


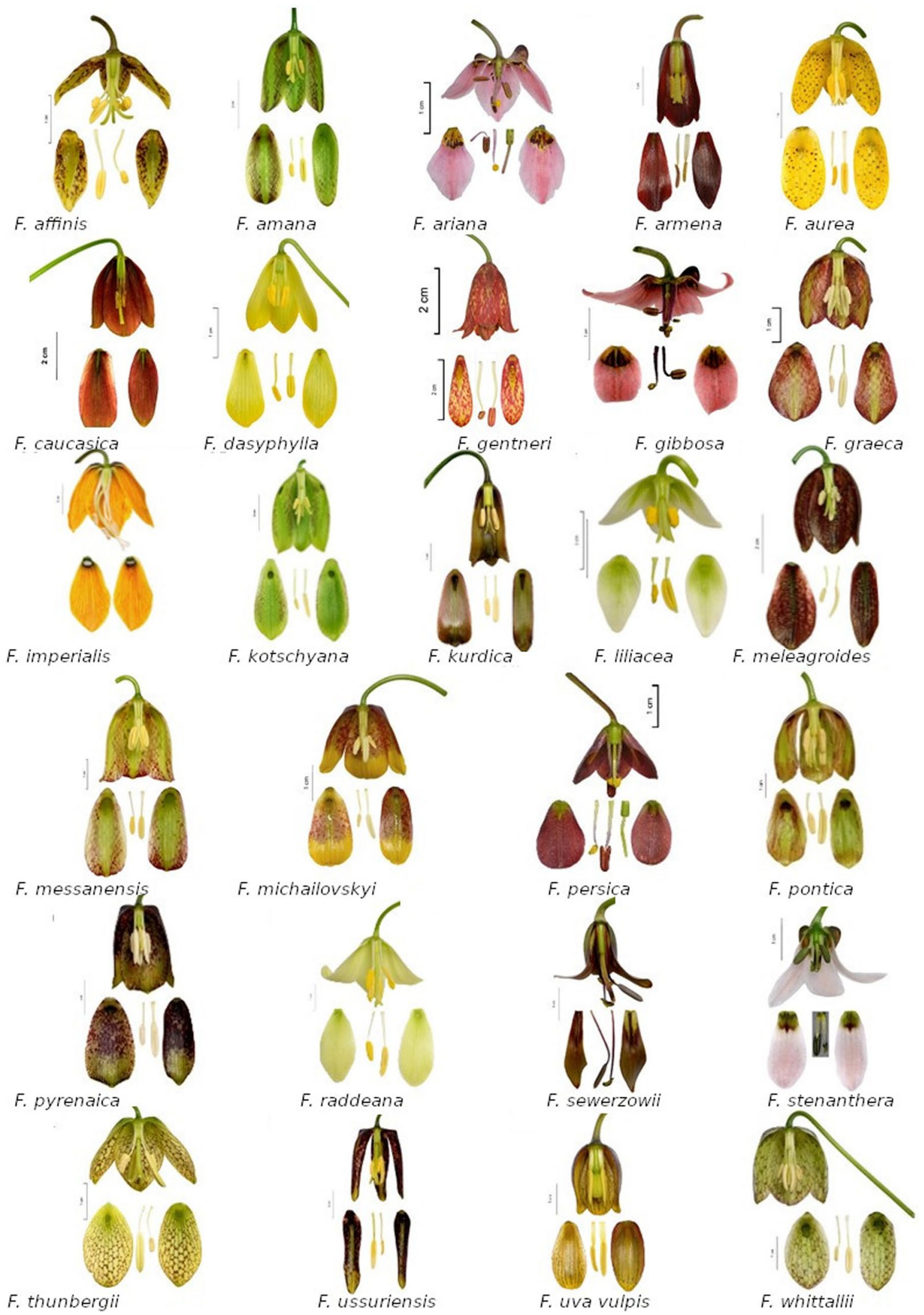

Figure 1. Flowers of some Fritillaria species presented in the study (pictures by LH). The images were produced using GNU Image Manipulation Program (GIMP) 2.99.4 (https://www.gimp.org). 
the BG collection were sampled directly prior to analysis. Flowers from the collections of CE, LH and PK were collected and stored in a refrigerator $\left(4^{\circ} \mathrm{C}\right)$ for three to five days before analysis. Storing flowers at a low temperature may potentially change the spectral reflectance of collected specimens, yet to the best of our knowledge, this is one of most common ways of preserving flower colours.

For the collected flowers, we measured the reflectance of all the dominant-coloured areas of the tepals (the most widespread colours within a flower, with the assessment of colour based on human perception) inside and outside of the flowers. Additionally, reflectance was measured for the nectaries (scheme showing the analysis pattern in Supplementary materials Fig. 2). The reflectance curves represent a mean value of five measurements from one flower (prepared using Python version 3.7).

The reflectance measurements were performed with a JAZ Spectrometer System (Ocean Optics Inc., Florida, USA) at an angle of $45^{\circ}$ to the measurement site (connected via a fibre-optic cable; UV-VIS $400 \mu \mathrm{m}$; World Precision Instruments, Inc., Florida, USA). To calibrate the spectrometer, we used a black standard (black PTFE powder, Spectralon diffuse reflectance standard SRS-02-010, reflectance factor of 2.00\%, Labsphere, Inc., North Sutton, USA) and a white standard (white PTFE powder, Spectralon diffuse reflectance standard SRS99-010, reflectance factor of $99.00 \%)$.

To analyse the spectra according to a potential pollinator's visual system, we used the vismodel function in the 'pavo' package. This tool enabled us to show the reflectance spectra in combination with colour-space models of pollinator vision (settings of the vismodel analysis in Supplementary materials S1). We analysed the visual systems of bees (Apis mellifera), flies (Musca domestica and Eristalis tenax), butterflies (Pieris rapae) and birds (Cyanistes caeruleum, a passerine bird, and Sephanoides sephaniodes, a hummingbird). These species were selected as representatives of potential pollinator groups based on the literature $e^{41,42,53-56}$. Prior to analyses, the reflectance data were smoothed, and the negative values were set to 0 (procspec function in the 'pavo' package).

To find out more about bee vision and test for the presence of nectar guides in fritillaries, we took pictures with several filters (for details, see below). Subsequently, we prepared false-colour pictures of Fritillaria flowers. Many details of fritillary flowers, such as colour patterns (produced by chequered tepals), nectaries, and stamens, are too finely scaled for spectral reflectance measurements. We applied false-colour photography to reveal these colour patterns. These analyses were performed for 34 Fritillaria species (Fig. 1, Supplementary materials Table 1). Photographs of the flower details were taken by using a UV-sensitive Nikon D60 (Tokyo, Japan) camera, which was then combined with a filter transmitting human-visible light (UV/IR cut filter: Baader UV-IR-Cut/L-filter) or a UV-transmittance filter (Baader U-filter 2, transmission peak wavelength $350 \mathrm{~nm}$, half-bandwidth $60 \mathrm{~nm}$; Baader Planetarium, Mammendorf, Germany), in daylight. The false-colour images of Fritillaria flowers were prepared in Photoshop (version CS5) according to the procedure described in Luanau and VerhoeVen ${ }^{58}$.

Phylogenetic tree. To understand the evolutionary tendencies of the floral traits of fritillaries, we constructed a phylogenetic tree for phylogeny-based analysis. We used the nuclear ITS (DNA internal transcribed spacer) and the plastid genes matK and rpl16. We used Lilium L. as an outgroup based on the established relationship ${ }^{43,49}$. All of the gene sequences were acquired from GenBank (accession numbers in Supplementary Materials S2) and downloaded using the MatPhylobi program ${ }^{59}$, which is a command-line tool for constructing taxonomic data sets for phylogenetic inference based on NCBI data. To create the phylogenetic database in MatPhylobi, we seeded F. michailovskyi and L. regale as representatives of the studied genera. The sequences downloaded represent 113 Fritillaria species.

All three types of sequences were independently aligned using the online implementation of the multiple alignment program MAFFT (version $7.64^{60}$ ). Subsequently, all alignments were imported into a modular system for evolutionary analysis, called Mesquite (version 3.6 $6^{61}$ ), for visual inspection. Poorly aligned positions and divergent regions were eliminated using TrimAl (version 1.3, http://phylemon2.bioinfo.cipf.es). The trimmed alignments were then concatenated with RAxML, a tool for phylogenetic analysis (version $8.0^{62}$ ).

Using the combined data set, we estimated the divergence time of Fritillaria. To do so, we used a log normal relaxed clock in BEAST 2 version 2.6.3 ${ }^{63}$. On the basis of the jModelTest results, we used GTR as the substitution model. We specified the tree prior model as the fossilized birth-death model and calculated the posterior distributions of internal nodes with Markov chain Monte Carlo (MCMC) analyses of 10 million generations with a $10 \%$ burn-in. To calibrate the tree, we used four dated fossils for Liliales previously used in Fritillaria dating ${ }^{64}$ : Luzuriaga peterbannisteri (age range: 23.03-15.97 Ma; in our study, we set the age to $20 \mathrm{Ma}$ ), Smilax labidurommae ${ }^{65}$ (age range: 37.2-33.9 Ma; in our study, we set the age to $35 \mathrm{Ma}$ ), S. pristina ${ }^{66}$ (age range: $55.8-48.6 \mathrm{Ma}$; in our study, we set the age to $51 \mathrm{Ma}$ ), and Ripogonum tasmanicum ${ }^{67}$ (age range: $55.8-48.6 \mathrm{Ma}$; in our study, we set the age to $51 \mathrm{Ma}$ ). We set the mean and standard deviation of these distributions to 1 and 1.25, respectively, and the confidence interval to $10 \mathrm{Ma}$.

Using our refined database of sequences, we also used RAxML to generate our final phylogenetic tree for ancestral state analysis. RAxML uses a series of maximum-likelihood (ML) tests to generate the tree. To find the best phylogenetic tree, we used a bootstrap analysis with 1000 replicates for each of the partitions (with models recommended by PartitionFinder $\left.{ }^{68}\right)$.

Data collection-nectar properties, floral traits, and species distribution. To better understand plant-pollinator communication in Fritillaria, we prepared a database describing the diversity of nectar properties and several floral traits that are potentially important for increasing attractiveness in the studied genus. Our sources were scientific literature describing fritillaries, regional floras, and internet sources (http://www.fritillari aicones.com, http://www.efloras.org, and http://www.fritillaria.org.uk). Supplementary materials Table 1 presents all the data. We assessed available information for nectar properties and six floral traits for 113 species present on the phylogenetic tree. 
Nectar properties, i.e., volume and sugar concentration, were obtained from Roguz ${ }^{38,41}$. In that study, the authors measured the volume of nectar collected from flowers during anthesis. Flowers for nectar sampling were bagged with mesh during the bud stage to prevent visits by insects. During anthesis but before anther dehiscence, nectar was sampled. All samples assigned to a specific treatment were analysed with the use of the same methods. Sample size varied depending on the species, with a range from four to 70 (Supplementary materials Table 1).

All the studied fritillaries produce nectar, which is easily accessible to pollinators; however, nectaries are usually hidden within the nodding perianth. We assessed the number of species where flowers are not facing down and wide open with visible nectaries. Additionally, we counted species where the nectary presents contrasting colours. Several pollinators visit flowers mainly for pollen ${ }^{61}$; therefore, their presentation may play a crucial role in luring potential pollinators. Therefore, we calculated the number of Fritillaria species with anthers visible from a distance, i.e., flowers with a wide open perianth (e.g., F. bucharica) or with the anthers exerting beyond the perianth (e.g., F. imperialis). Fritillaria is one of very few genera where a chequered pattern covers the tepals, so we also collected information regarding the presence or absence of this pattern on the tepals. To estimate the visual attractiveness of the flowers, we collected information about the size of the flowers, i.e., entrance diameter (entrance to the flower at the widest point) and the length of the tepals.

To assess the differences among Fritillaria species, we collected information about the distributions of modern representatives of this genus. We defined five distributional areas, namely, North Africa, Asia-temperate, Asiatropical, Europe, and North America, and a combination of these distributions.

Phylogenetic studies. Next, using the obtained tree and trait databases, we determined the ancestral states of reward presentation, the chequered pattern, and the species distribution. The analysis was performed using single rate model reconstruction, which gives empirical Bayesian probabilities ('ape' package, version 5.0 ${ }^{69}$ ). First, we determined the appropriate transition probability model, choosing among ER-equal rate, SYM-symmetrical rate, and ARD_-all-rates different, using a log likelihood ratio analysis. In all cases, the ARD transition ratio model was chosen because it had the highest likelihood value. Then, to compute the total number of character changes, as well as the number of character changes between all states, we used the make.simmap function in the 'phytools' package (1000 simulations across the tree ${ }^{70}$ ).

Finally, using the phylogenetic tree of Fritillaria, we tested for correlations between continuous traits and nectar properties (nectar volume, sugar concentration, entrance diameter and tepal length) and discrete traits (anther and nectary presentation, colour of the nectaries, presence of the chequered pattern and species distribution). We conducted phylANOVA on other visual traits (performed in $\mathrm{R}$ using the phylANOVA function in the 'phytools' package). This function performs the simulation-based phylogenetic ANOVA of Garland and Jones ${ }^{71}$. The level of correlation between the continuous traits was assessed by calculating the phylogenetic generalized least squares (PGLS). In this study, the structure of the phylogenetic signal was controlled by the lambda parameter. The branch length transformation was optimized between bounds using maximum likelihood ('caper' package, version $\left.\mathrm{v} 1.10 .1^{72}\right)$. The statistical analyses were performed with the statistical computing software $\mathrm{R} 3.5 .3^{73}(\mathrm{R}$ analysis code accessible in Supplementary materials S3).

\section{Results}

Spectral analysis. For most of the studied fritillaries, the reflectance was higher above $500 \mathrm{~nm}$ and lower in the blue and UV wavelength range. Species with bright flowers (white or pink) were an exception, with reflectances higher above $350 \mathrm{~nm}$. The ultraviolet reflectance properties of Fritillaria species varied within subgenera, with no obvious pattern of UV reflection. For example, the subgenus Fritillaria includes UV-reflecting species (F. montana) and UV-absorbing species (F. graeca). Closely related F. imperialis and F. eduardii, representing the subgenus Petilium, had UV-absorbing tepals and UV-reflecting stigmas (Fig. 2; Supplementary materials Fig. 3). Flowers of Fritillaria ariana displayed a UV bull's eye pattern with a UV-reflecting centre. Additionally, flowers of F. liliacea had a UV-absorbing centre. The species with chequered tepals had UV-reflecting white dots (Fig. 3).

For almost all Fritillaria species, the reflectance of the nectaries was much lower than that of tepals. Only the nectaries of F. eastwoodiae, F. dasyphylla and F. minima had reflectances similar to or higher than the values recorded for the tepals. The reflectances of the inner and outer sides of the tepals were similar (Figs. 2, 3; Supplementary materials Fig. 3).

False-colour pictures indicated that the nectary area in fritillaries is distinctive. As a result, nectaries may act as visible nectar guides for bees. The anthers and pollen grains, mostly yellow under human vision, proved to be visible to bees in both insect- and bird-pollinated flowers. The chequered pattern present on the tepals of some species was also visible to bees. The nectaries of the subgenus Petilium had an accumulation of starch, producing a white appearance, which was also confirmed in the false-colour pictures (Fig. 3). Bird-pollinated species of fritillaries, i.e., F. imperialis, F. gentneri and F. recurva, are visible to pollinators, with distinctive anthers and nectary areas.

Modelling of fritillary flower colour appearance in the chromaticity diagram of Apis mellifera and Eristalis tenax showed that the studied species densely occupied the portions of long waves: the centre and around the corner with long wavelengths. Bird-pollinated Fritillaria flowers occupied the same sections. In the case of Musca domestica, the model also showed a large accumulation of species presumably pollinated by insects in the corner representing long waves. Species pollinated by passerine birds were located closer to the green photoreceptor type. For Lepidoptera, represented by Pieris rapae, all fritillaries occupied mostly the centre of the diagram. For potential bird pollinators, both representatives of hummingbirds and passerine birds, mostly possessing cones with long- and medium-wavelength sensitivities, were stimulated. The accumulation of most points in the $1 \mathrm{~m}$ range suggested the stimulation of cone oil droplets with carotenoid filters (Fig. 4). 

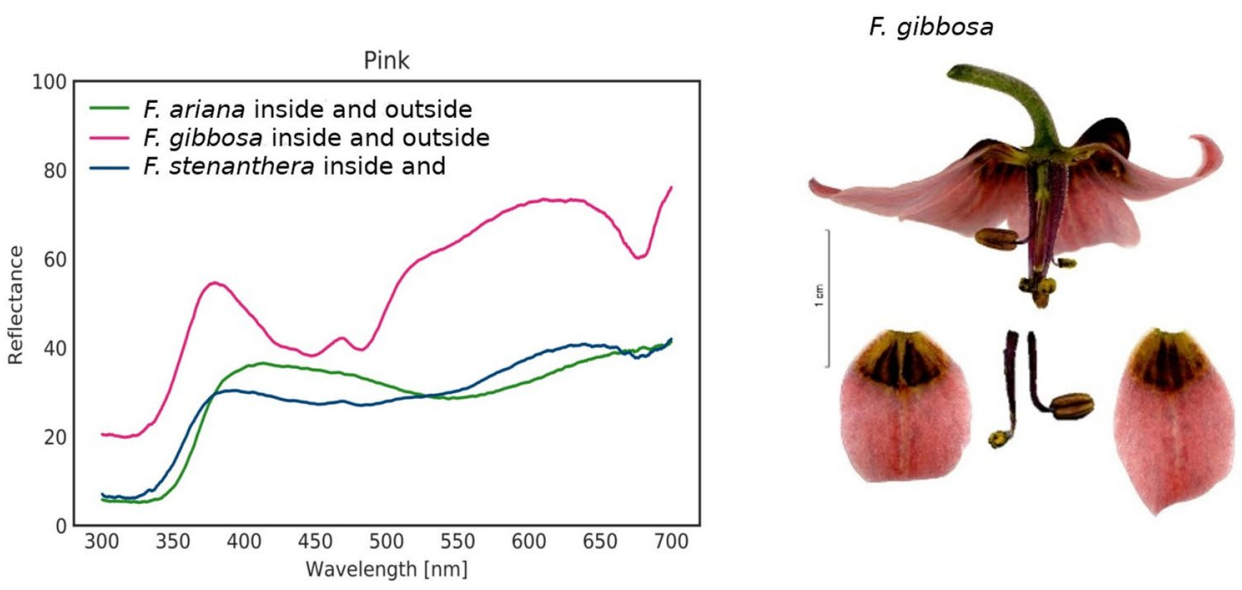

F.gentneri
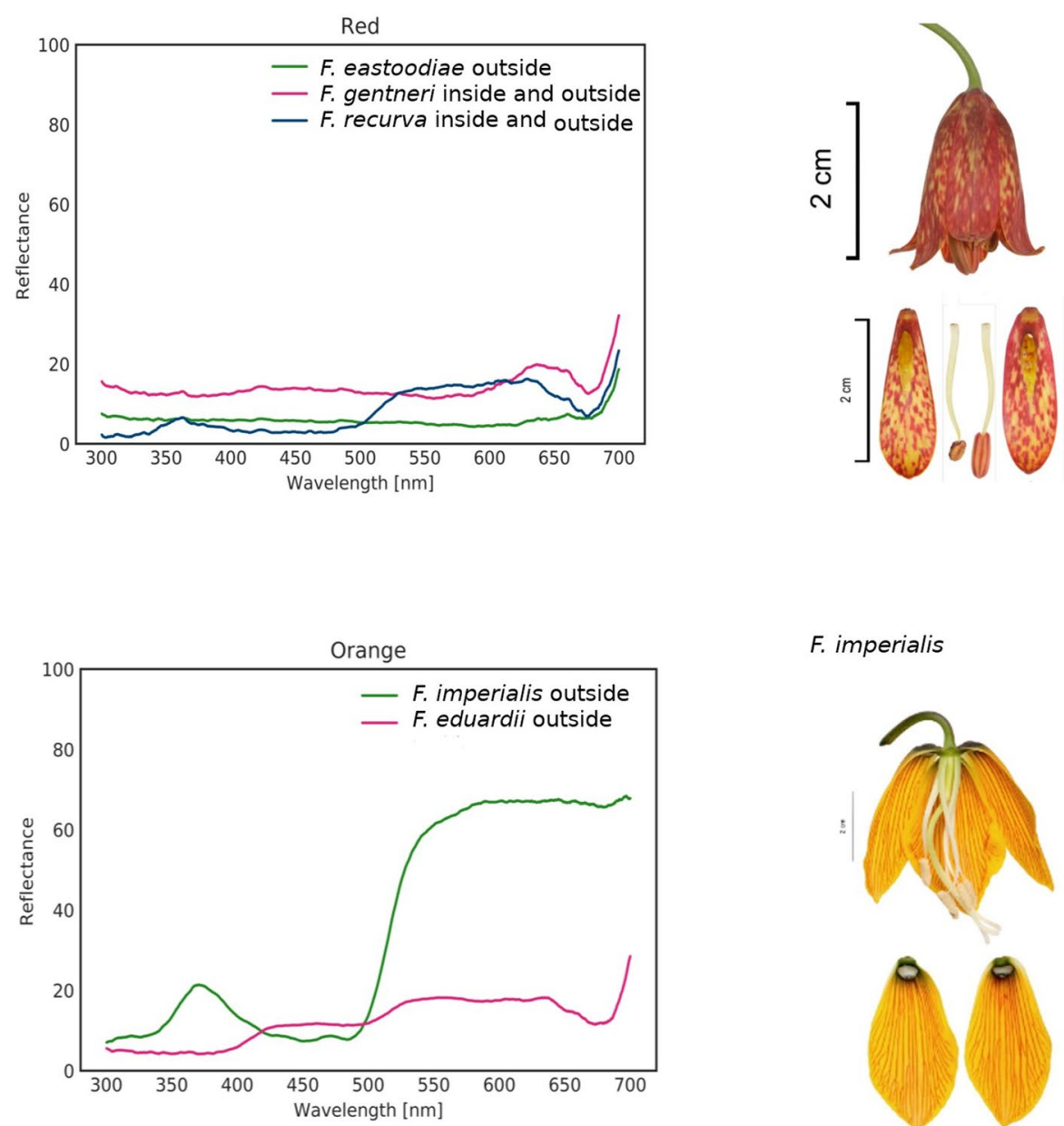

F. imperialis

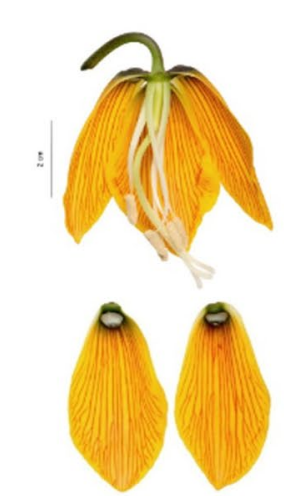

Figure 2. Reflectance of Fritillaria flowers of the same colour category representing different subgenera and exemplary species representing the colour category. Species with bright flowers (pink) have high reflectance above $350 \mathrm{~nm}$. Reflectance of the nectary area was much lower than that of tepals for most of the studied Fritillaria species. The images were produced using GNU Image Manipulation Program (GIMP) 2.99.4 (https:// www.gimp.org). 

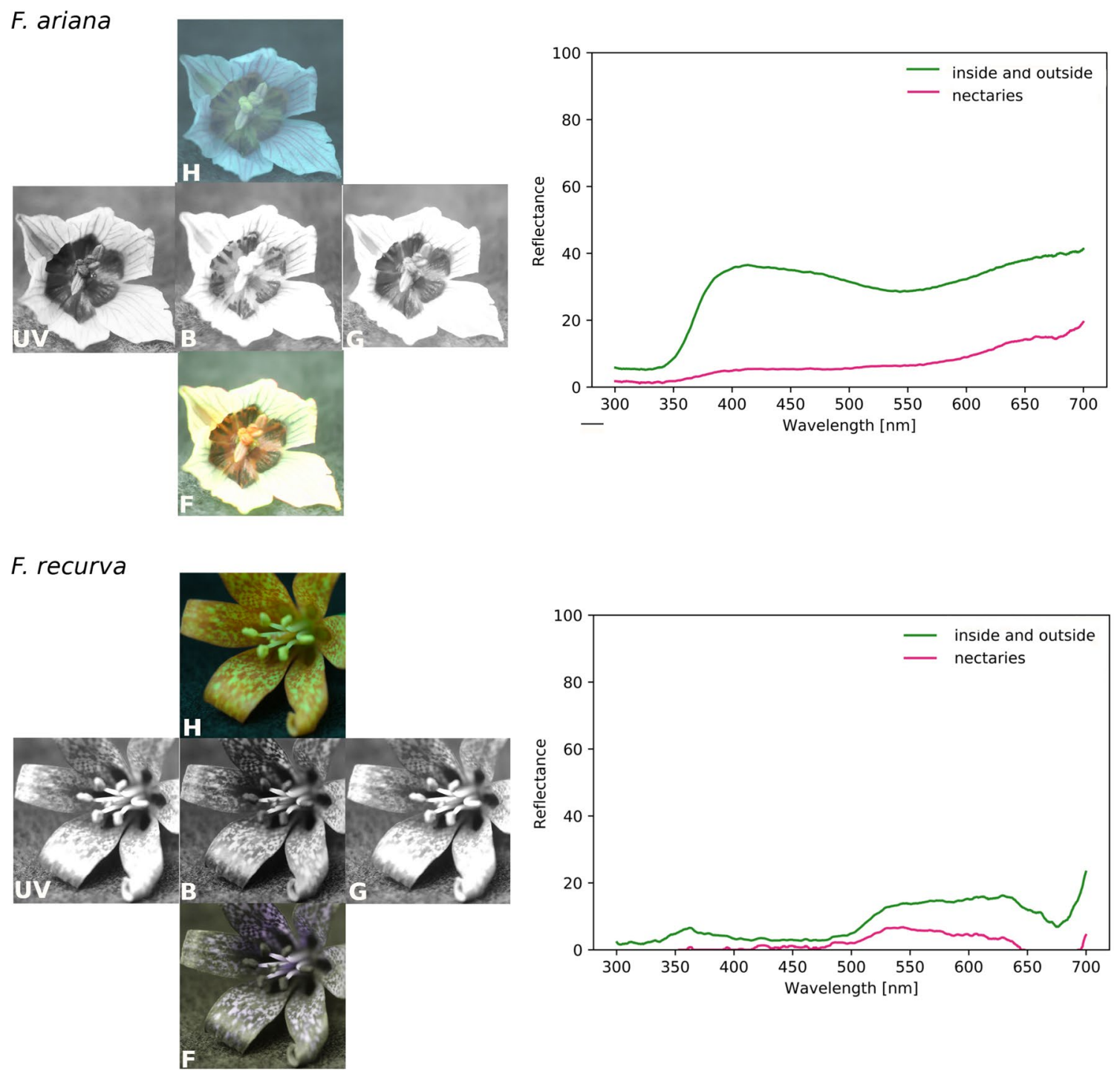

\section{F. imperialis}
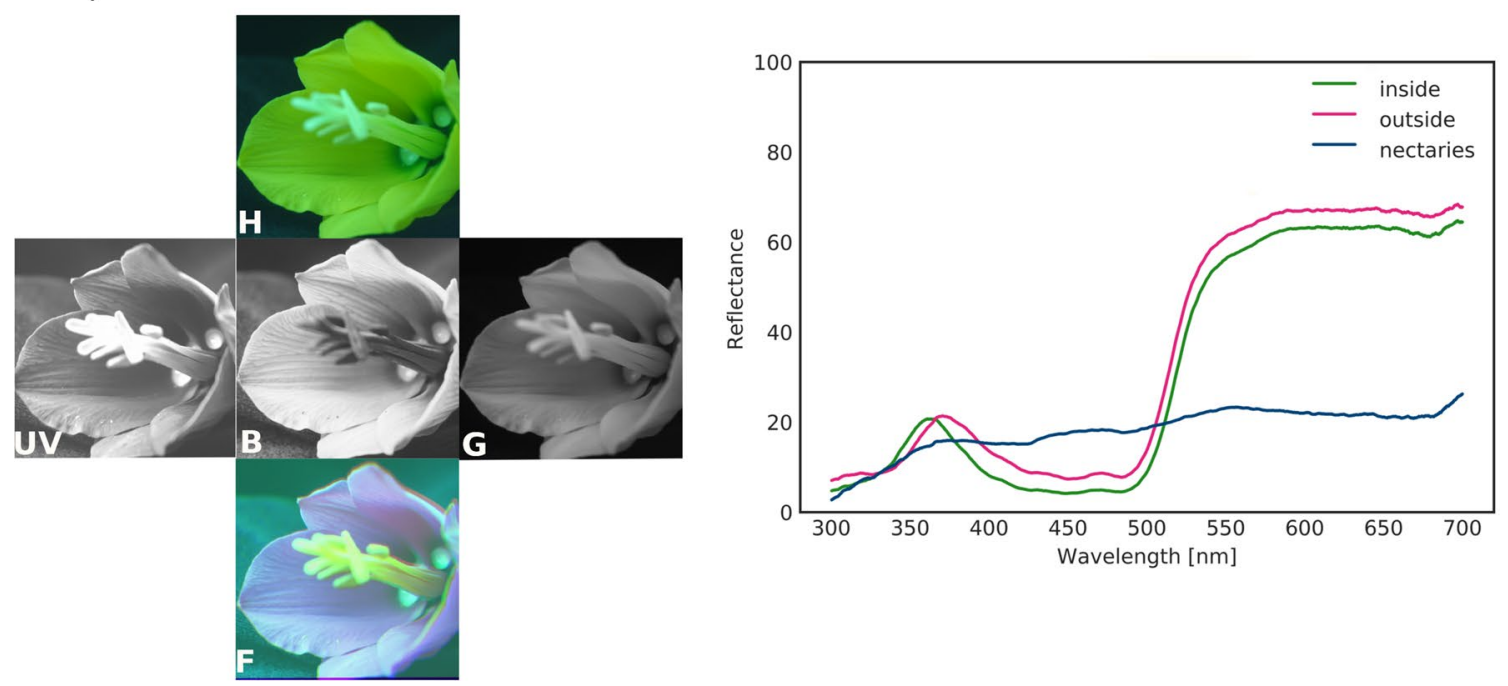

Figure 3. Colour photograph (human vision; H); UV (UV), blue (B), and green photographs (G); false-colour pictures (bee vision; F); and reflectance curves for selected Fritillaria species. Fritillaria ariana displayed a UV bull's eye pattern (UV-reflecting centre of the flower) and had relatively high reflectance in the UV range. American F. recurva and F. gentneri had UV-reflecting white dots in the chequered tepal pattern. F. imperialis had UV-absorbing flowers with the exception of UV-reflecting stigmas. Reflectance of the nectary area was much lower than that of the tepals for most of the studied fritillaries. The images were produced using GNU Image Manipulation Program (GIMP) 2.99.4 (https://www.gimp.org). 
A

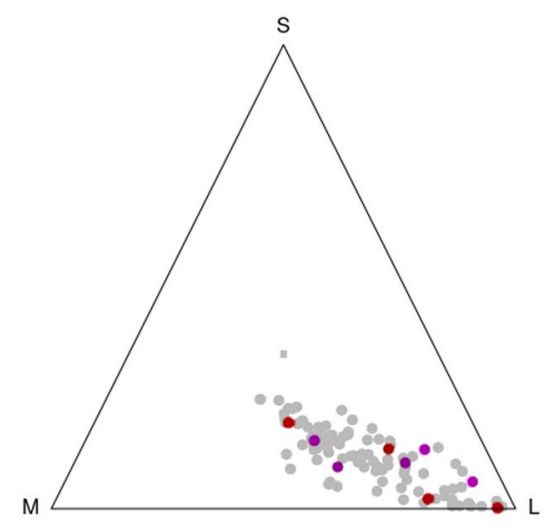

D

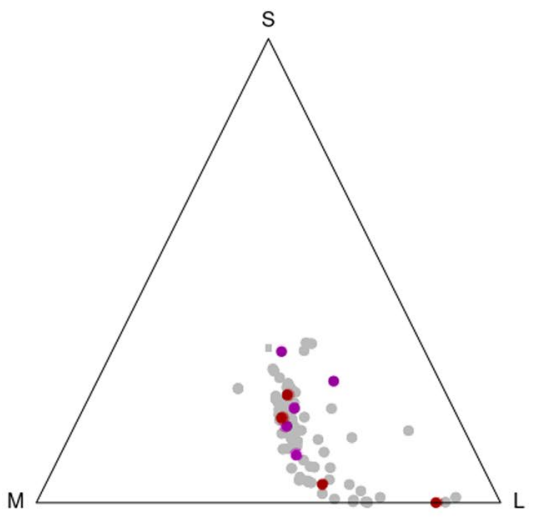

B

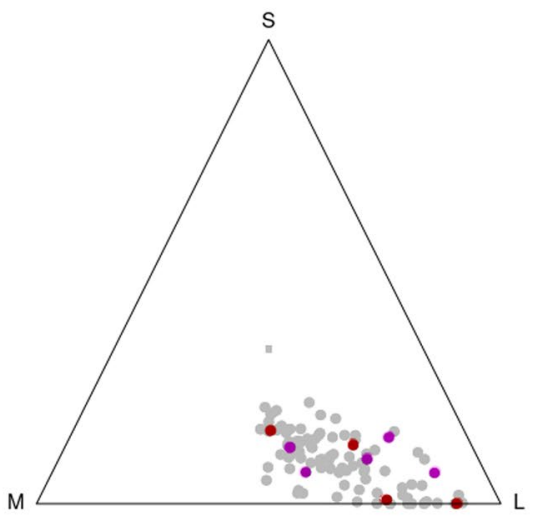

E

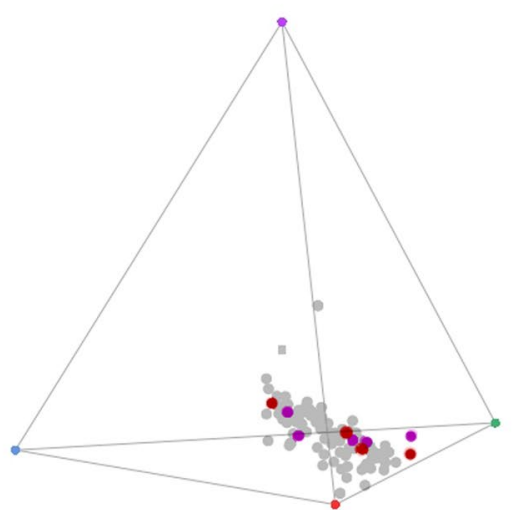

C

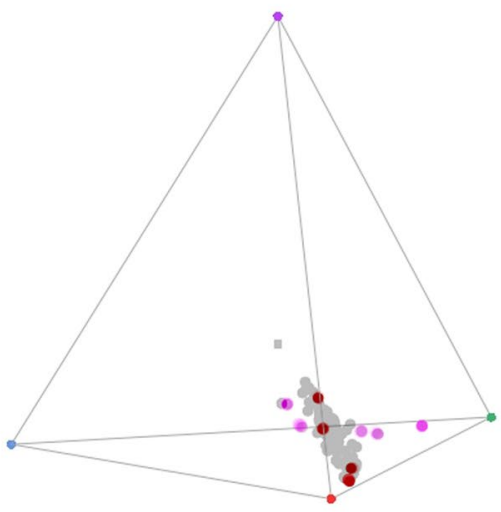

F

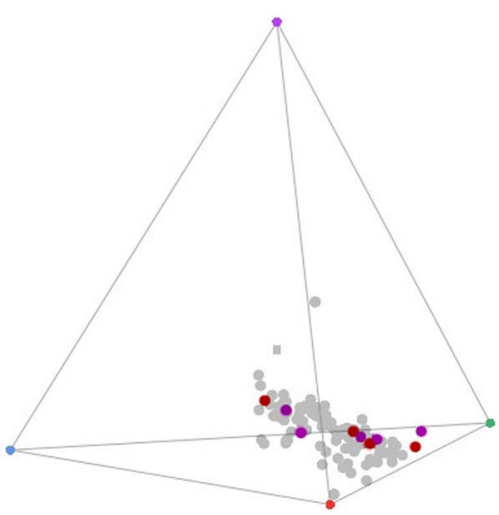

Figure 4. Colour loci in a $\mathrm{CH}$ model, where the triangle tops represent the wavelength: $\mathrm{S}-$ short, $\mathrm{M}-$ medium and L-long. Colour loci are shown in the tetrahedron colour spaces. The inverted triangles in the centres refer to the origin points; purple, blue, green and red vertices represent the maximum signals (relative quantum catches). Pink dots represent passerine bird-pollinated species, red dots represent hummingbird-pollinated species, and grey dots represent the rest of the studied species. Models for bees ([A] Apis millifera), flies ([B] Eristalis tenax, $[\mathbf{C}]$ Musca domestica), butterflies ([D] Pieris rapae), and birds ([E] the hummingbird Sephanoides sephaniodes and $[\mathbf{F}]$ the passerine bird Cyanistes caeruleus). The images were produced using GNU Image Manipulation Program (GIMP) 2.99.4 (https://www.gimp.org).

Flower traits, nectar properties, pollinators, and species distribution. All the studied Fritillaria species produced nectar, which is an important reward for pollinators. Its concentration and volume were variable, ranging from 5.3 to $64.9 \%$ and from 0.3 to $205 \mu$ per flower, respectively.

The flowers were usually bell-shaped and nodding, and as a result, nectaries and anthers were not visible to approaching animals. In general, $13.9 \%$ of fritillaries (16 species) had nectaries visible from the outside, and $21.7 \%$ ( 25 species) had anthers that may be perceived from a distance. The nectaries usually had different colours than the background (75.6\%, 87 species). The chequered pattern was common among the Fritillaria species, where $54 \%$ (61 species) had spotted tepals. The perianth entrance diameter and the length of the tepals were variable and depended largely on the species, with ranges from 9.3 to $67.8 \mathrm{~mm}$ and 10.5 to $53.2 \mathrm{~mm}$, respectively.

The relationships among the studied features-phylogeny-based analyses. Fritillaria was estimated to have originated approximately $38 \mathrm{Mya}$, in the early Oligocene (Fig. 5). The most recent common ancestor of Fritillaria occurred in temperate Asia, where the highest diversity of fritillaries is still found (Supplementary materials Fig. 4). Expansion to North America occurred early in the evolution of this genus. Species pollination by passerine birds evolved earlier (approximately $27.5 \mathrm{Mya}$ ) and hummingbird-pollinated species appeared recently in the phylogeny of the studied genus (approximately $24 \mathrm{Mya}$ ).

The ancestral state reconstruction in Fritillaria suggests that the most recent common ancestor probably had flowers with nectaries hidden deeply within the perianth but with a distinctive colour (Supplementary materials Fig. 5A,B). Both of these states were also the most common across the phylogeny and among modern species 


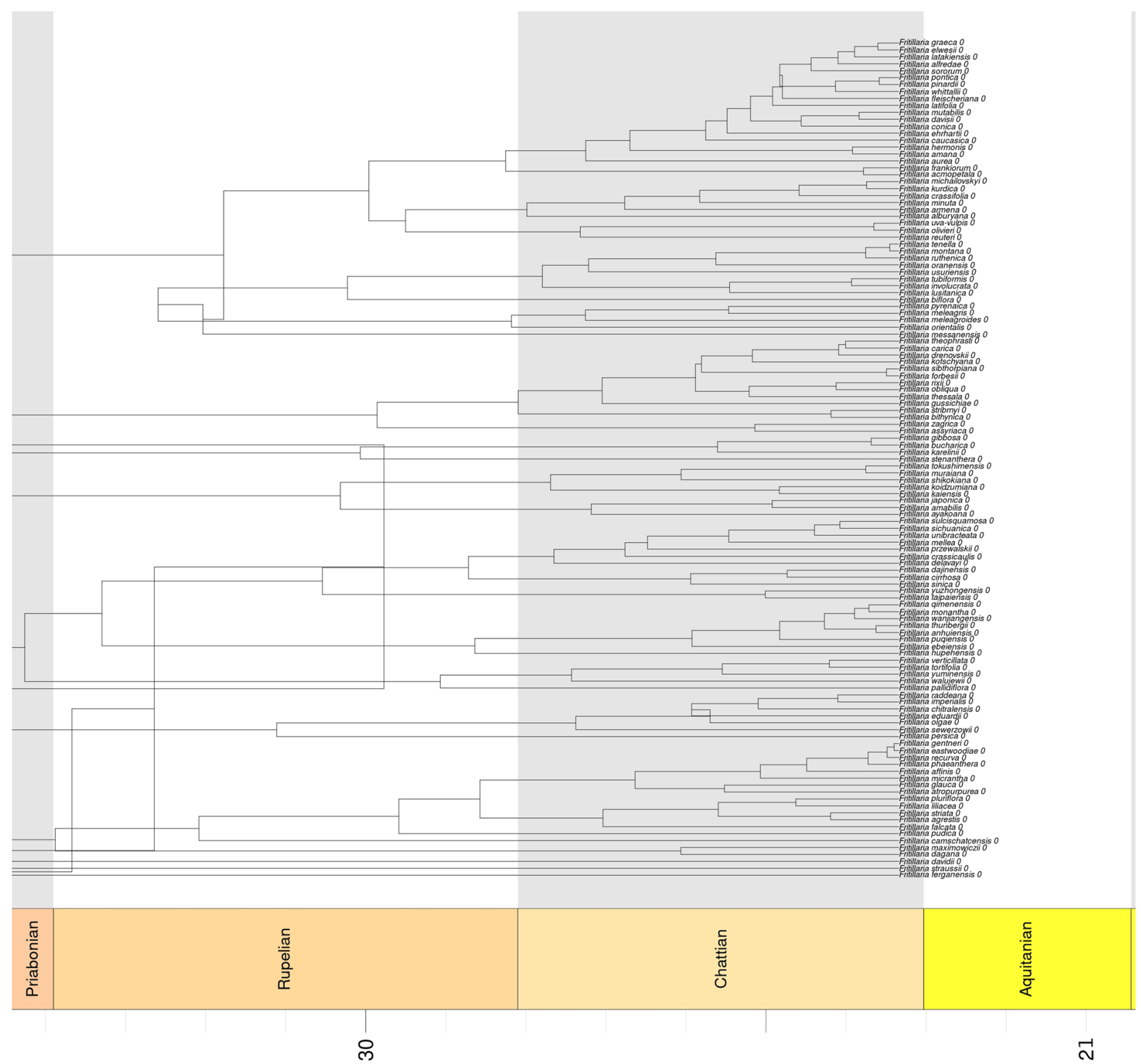

Figure 5. The maximum clade credibility tree of Fritillaria summarized by TreeAnnotator and plotted with a geological timescale using the strap package geoscalePhylo function in $\mathrm{R}$. The timeline at the bottom indicates the age (Mya, million years ago) of nodes.

(Supplementary materials Table 2). The anthers of most fritillaries are and always have been not visible from a distance (Supplementary materials Fig. 5A,B). Even when visible nectaries and/or anthers evolved, these features were lost several times. The chequered pattern also evolved early during the evolution of this genus. The majority of internal nodes had a pattern on the tepals. Several subgenera, such as Petilium, Theresia and Korolkovia (species representing the subgenera mentioned in Supplementary materials Table 1), appear to have arisen from an ancestor with chequered patterns on the tepals, with recent loss of this character (Supplementary materials Fig. 5A,B). All the studied flower features were labile, with the highest number of changes observed for the presence or absence of the chequered pattern (747 shifts between the states) and the lowest for the visibility of the anthers (56.8, Supplementary materials Table 2).

Taking into account the phylogenetic relationships among fritillaries, we did not find associations between floral traits and nectar properties (Supplementary materials Table 3). Testing for correlations between the studied characters with PGLS, we found only two significant negative correlations: between entrance diameter and tepal length $(r=-0.09, p$ value $<0.05)$ and between nectar volume and entrance diameter $(r=-0.02, p$ value $<0.05$, Supplementary materials Table 4 ). 


\section{Discussion}

The flowers of fritillaries show a wide diversity of colours and colour patterns. In this study, we assess the attractiveness of Fritillaria flowers to potential pollinators and search for correlations between visual traits and reward properties. We also track the evolutionary tendencies of floral traits related to reward presentation. Most Fritillaria flowers reflect wavelengths $>500 \mathrm{~nm}$, while hymenopteran pollinators are likely to have the best discrimination for wavelengths close to $400 \mathrm{~nm}$ and $500 \mathrm{~nm}^{74}$. Therefore, the plant-pollinator relationship in fritillaries seems to be based on robust food rewards; however, these rewards are not advertised. Neither flower entrance diameter nor tepal length is correlated with nectar properties. Most of the modern species also have both nectaries and anthers hidden deeply in a nodding perianth, which is also the most likely state of the recent common ancestor.

When pollinators are in the flower, the nectaries are distinctive, and their colours differ from that of the background. Different nectary colour is and has been common among fritillaries. Red and orange flowers are found only among bird-visited fritillaries. The principles of the pollination syndrome theory, however, may be applied to fritillaries only to a limited extent. Flowers of these species are also visited by bees, suggesting ecological generalization, despite some level of phenotypic specialization. One of the reasons for this ${ }^{75}$ may be relatively late diversification. Fritillaries originated approximately $38 \mathrm{Mya}$, with the most recent common ancestor found in temperate Asia, but specific pollination syndromes appeared later. For example, species pollinated by hummingbirds appeared approximately 24 Mya.

False-colour pictures prepared for fritillaries proved that flower colours of bird-pollinated species and the rewards within were visible to bees. This also confirms observations from natural habitats, where North American red-flowered fritillaries are visited by bees ${ }^{55}$. It is important to note that among fritillaries, an evolutionary transition from purple to red flowers is common ${ }^{51}$. This type of shift often accompanies shifts in adaptation from bee to hummingbird pollination or co-occurs with other floral adaptations that facilitate hummingbird pollination $^{76}$. Several studies proved the attractiveness of red-flowered species to insects ${ }^{77-79}$; however, to protect the reward, some hummingbird-pollinated flowers reflect mostly long-wavelength light (median wavelengths $>585 \mathrm{~nm}$ ), as this decreases their visibility and helps avoid visits by illegitimate pollinators ${ }^{7,16}$. This was not the case for the studied species, which may be related to their relatively recent evolution. Hummingbird-pollinated fritillaries evolved in North America and are absent in Europe and Asia. Due to this relatively recent evolution, hummingbird-pollinated fritillaries probably had no chance to adapt to these birds in the Old World ${ }^{80,81}$.

Similarly, as in the case of hummingbird-pollinated flowers, passerine bird-pollinated fritillaries are also visible to insects. Flowers of these species also have distinctive colouration within the genus: typically, orange-red (rarely yellow) flowers that lack reflectance in the UV range. As with hummingbird-pollinated North American fritillaries, it is still unclear why Asian bird-pollinated F. imperialis and F. eduardii exhibit this colouration or if passerine birds have a preference for these colours. We assume that tepal colour is an important long-distance signal ${ }^{57}$, although the rewards reflecting the preference of these pollinators (hexose- and amino acid-rich nectar, lacking sucrose $\mathrm{e}^{40,41}$ in passerine bird-pollinated flowers and very large amounts of nectar with low amino acid concentrations in hummingbird-pollinated species) are equally important. The observed ecological generalization, despite some level of phenotypical specialization ${ }^{75}$, observed in fritillaries may be a result of relatively shortduration fritillary-bird interactions. Studies testing the evolution of flower colour and rewards in members of this genus suggest that changes in these flower features may have appeared only recently ${ }^{52}$, and Asian F. imperialis and F. eduardii flowers visited and pollinated by passerine birds ${ }^{53,54}$ probably evolved approximately 27.5 Mya.

Despite the importance of visual floral traits in shaping plant-pollinator interactions ${ }^{82}$, we did not find visual attractants described as important for insect pollinators ${ }^{83-85}$ in most of the studied species. For example, our analyses indicated overall UV absorbance and did not indicate additional ultraviolet-reflecting areas. UVreflecting flower parts are common among insect-pollinated species ${ }^{7,86}$, e.g., in yellow bee-pollinated flowers ${ }^{86,87}$, where they form the so-called bull's eye pattern with a UV-reflecting periphery and UV-absorbing centre ${ }^{88}$. In fritillaries, we detected the bull's eye effect in species with bright pink flowers, namely, F. ariana, F gibbosa and F. stenanthera. These closely related species have wide open, erect flowers; therefore, we assume that the angle of the flower may correlate with the presence of the bull's eye pattern-it could not be seen in downward-facing bell-shaped flowers. The lack of a strong visual signal, common among fritillaries, is most likely caused by the thick wax cover present in almost all fritillaries ${ }^{41}$. Additionally, the similarity of the reflectance curves found in our study may be due to the similarity of tepal ultrastructure in Fritillaria, which may determine the reflectance amplitude $^{89}$. Previous studies conducted by Roguz ${ }^{39}$ revealed that almost half of the genus has nearly the same tepal and nectary ultrastructure.

We assume that in fritillaries, where the reflectance does not fit the preferences of the most important pollinators, visual signals perceived from a short distance may play an important role. The presence of the chequered pattern, although labile, evolved early in fritillary diversification and is very common among modern species. The chequered pattern, rare among other plant species, can enhance flower attractiveness ${ }^{90}$ by increasing the contrast between the object and background through motion parallaxis ${ }^{91}$. Such purple-yellow mottled tepals, common among fritillaries, can also increase the attractiveness of their flowers to flies. These insects are pollinators of at least one fritillaria species (F. camschatcensis ${ }^{56}$ ) and have been seen visiting several other species (authors' observations).

Additionally, nectaries and anthers, hidden deeply within a nodding perianth, are common and conserved states. In most of the fritillaries, the placement of the reward is "highlighted" by nectaries in different colours, and contrasting nectaries evolved early and are frequent among modern species. Previous studies on Fritillaria revealed a lack of phylogenetic signal for nectar properties. These traits show high variability at the community level, which might suggest adaptive evolution in response to different environmental conditions ${ }^{27}$. These variabilities in Fritillaria nectar volume and concentration may also be a reason for the lack of correlations between 
floral traits and nectar properties. These results, however, are surprising, since several studies have shown an association between flower size and rewards ${ }^{27,32,92}$. Nevertheless, the most luring advertisement is to display the reward itself, which then confers the dual role of both signal and reward ${ }^{93,94}$. Open flowers with nectar displayed in the form of large droplets and bright yellow pollen contrasting with the dull flower evolved in Fritillaria only a few times. Both of these traits were lost several times across the phylogeny.

Although plant pollinators are among the most important factors influencing visual floral traits, their variability may also be maintained by selection related to environmental heterogeneity. Two of the most common colours in the case of Fritillaria flowers are green and purple, which may be related to random or non-adaptive processes maintaining flower colour variation ${ }^{95}$. However, this colour polymorphism may also be related to the ecological role of the pigments responsible for this type of colouration. Studies by Bazzaz and Carlson ${ }^{96}$ revealed, for example, that the photosynthetic activity of green flowers may be enough to maintain their own structure. On the other hand, floral pigments such as anthocyanins, related to violet-purple colouration, function in response to plant stress caused, e.g., by drought, cold or nitrogen deficiency.

\section{Conclusions}

The attractiveness of Fritillaria flowers appears to be linked to early blooming and copious rewards. Flower signalling in Fritillaria seems to follow a rather simple pattern, with most flowers having almost uniform displays or occasional coloured peripheral and central parts of the flower. For animals already visiting the flowers, fritillaries have nectar guides in the form of contrasting nectary area colouration. This study and recent works on other aspects of pollination biology in Fritillaria indicate that plant-pollinator interactions may be responsible for a significant share of the floral diversity in the genus. The principles of the pollination syndrome theory, however, may be applied to fritillaries with some limitations. Flower colour does not play a role as a phenotypic filterred bird-pollinated fritillaries are also attractive to bees. The widespread purple and green colouration among Fritillaria, however, may potentially indicate some role of the environment in this trait. Clarifying the extent to which flower colour in Fritillaria is maintained by active selection pressures from pollinator preference and/or the environment remains an open question.

Received: 24 December 2020; Accepted: 5 May 2021

Published online: 26 May 2021

\section{References}

1. Warren, J. \& Mackenzie, S. Why are all colour combinations not equally represented as flower-colour polymorphisms?. New Phytol. 151, 237-241 (2001).

2. Armbruster, S., Fenster, C. \& Dudash, M. Pollination 'principles' revisited: specialization, pollination syndromes, and the evolution of flowers. Scandanavian Assoc. Pollinat. Ecol. 39, 179-200 (2000).

3. Hargreaves, A. L., Harder, L. D. \& Johnson, S. D. Consumptive emasculation: the ecological and evolutionary consequences of pollen theft. Biol. Rev. 84, 259-276 (2009).

4. Hansen, D. M., van der Niet, T. \& Johnson, S. D. Floral signposts: testing the significance of visual 'nectar guides' for pollinator behaviour and plant fitness. Proc. R. Soc. B Biol. Sci. 279, 634-639 (2012).

5. Rosas-Guerrero, V. et al. A quantitative review of pollination syndromes: do floral traits predict effective pollinators?. Ecol. Lett. 17, 388-400 (2014).

6. Narbona, E., Wang, H., Ortiz, P. L., Arista, M. \& Imbert, E. Flower colour polymorphism in the Mediterranean Basin: occurrence, maintenance and implications for speciation. Plant Biol. 20, 8-20 (2018).

7. Altshuler, D. L. Flower color, hummingbird pollination, and habitat irradiance in four neotropical forests1. Biotropica 35, 344 (2003).

8. Riordan, C. E., Ault, J. G., Langreth, S. G. \& Keithly, J. S. Cryptosporidium parvum Cpn60 targets a relict organelle. Curr. Genet. 44, 138-147 (2003).

9. Rodríguez-Gironés, M. A. \& Santamaría, L. Why are so many bird flowers red?. PLoS Biol. 2, 1515-1519 (2004).

10. Whibley, A. C. et al. Evolutionary paths underlying flower color variation in Antirrhinum. Science (80-.) 313, 963-966 (2006).

11. Papiorek, S. et al. Bees, birds and yellow flowers: pollinator-dependent convergent evolution of UV patterns. Plant Biol. 18, 46-55 (2016).

12. Wilson, P., Castellanos, M., Wolfe, A. D. \& Thomson, J. D. Shifts between bee and bird pollination in penstemons. Plant-Pollinat. Interact. Spec. Gen. 3, 47-68 (2006).

13. Wilson, P., Castellanos, M. C., Hogue, J. N., Thomson, J. D. \& Armbruster, W. S. A multivariate search for pollination syndromes among penstemons. Oikos 104, 345-361 (2004).

14. Sutherland, S. D. \& Vickery, R. K. Jr. On the relative importance of floral color, shape, and nectar rewards in attracting pollinators to Mimulus. Gt. Basin Nat. 53, 107-117 (1993).

15. Wester, P. \& Lunau, K. Plant-Pollinator Communication. Advances in Botanical Research Vol. 82 (Elsevier, 2017).

16. de Camargo, M. G. G. et al. How flower colour signals allure bees and hummingbirds: a community-level test of the bee avoidance hypothesis. New Phytol. 222, 1112-1122 (2019).

17. van der Kooi, C. J., Dyer, A. G., Kevan, P. G. \& Lunau, K. Functional significance of the optical properties of flowers for visual signalling. Ann. Bot. https://doi.org/10.1093/aob/mcyl19 (2018).

18. Castellanos, M. C., Wilson, P. \& Thomson, J. D. 'Anti-bee' and 'pro-bird ' changes during the evolution of hummingbird pollination in Penstemon flowers. J. Evol. Biol. 17, 876-885 (2004).

19. del Carmen Salas-Arcos, L., Lara, C., Castillo-Guevara, C., Cuautle, M. \& Ornelas, J. F. "Pro-bird” floral traits discourage bumblebee visits to Penstemon gentianoides (Plantaginaceae), a mixed-pollinated herb. Sci. Nat. 106, 1-11 (2019).

20. Armbruster, W. S. Evolution of floral morphology and function: an integrative approach to adaptation, constraint, and compromise in Dalechampia (Euphorbiaceae). Flor. Biol. https://doi.org/10.1007/978-1-4613-1165-2_9 (1996).

21. Chittka, L. \& Schürkens, S. Successful invasion of a floral market. Nature 411, 653 (2001).

22. Ellis, T. J. \& Field, D. L. Repeated gains in yellow and anthocyanin pigmentation in flower colour transitions in the Antirrhineae. Ann. Bot. 117, 1133-1140 (2016).

23. Tanaka, Y., Sasaki, N. \& Ohmiya, A. Biosynthesis of plant pigments: anthocyanins, betalains and carotenoids. Plant J. 54, 733-749 (2008). 
24. Lázaro, A., Lundgren, R. \& Totland, Ø. Pollen limitation, species' floral traits and pollinator visitation: different relationships in contrasting communities. Oikos 124, 174-186 (2015).

25. Jones, K. N. \& Reithel, J. S. Pollinator-mediated selection on a flower color polymorphism in experimental populations of Anthirrhinum (Scrophulariaceae). Am. J. Bot. 88, 447-454 (2001).

26. Teixido, A. L., Barrio, M. \& Valladares, F. Size matters: understanding the conflict faced by large flowers in mediterranean environments. Bot. Rev. 82, 204-228 (2016).

27. Ortiz, P. L., Fernández-Díaz, P., Pareja, D., Escudero, M. \& Arista, M. Do visual traits honestly signal floral rewards at community level?. Funct. Ecol. 35, 369-383 (2021).

28. Fenster, C. B., Cheely, G., Dudash, M. R. \& Reynolds, R. J. Nectar reward and advertisement in hummingbird. Am. J. Bot. 93, 1800 (2006).

29. Simpson, B. B., Neff, J. L. \& Simpson, B. B. Floral rewards: alternatives to pollen and nectar. Ann. Mo. Bot. Gard. 68, 301-322 (2015).

30. Canto, A., Herrera, C. M., García, I. M., Pérez, R. \& Vaz, M. Intraplant variation in nectar traits in Helleborus foetidus (Ranunculaceae) as related to floral phase, environmental conditions and pollinator exposure. Flora Morphol. Distrib. Funct. Ecol. Plants 206, 668-675 (2011).

31. Parachnowitsch, A. L., Manson, J. S. \& Sletvold, N. Evolutionary ecology of nectar. Ann. Bot. https://doi.org/10.1093/aob/mcy132 (2018).

32. Gómez, J. M. et al. Association between floral traits and rewards in Erysimum mediohispanicum (Brassicaceae). Ann. Bot. 101, 1413-1420 (2008).

33. Worley, A. C. \& Barrett, S. C. H. Evolution of floral display in Eichhornia paniculata (Pontederiaceae): genetic correlations between flower size and number. J. Evol. Biol. 14, 469-481 (2001).

34. Lunau, K. The ecology and evolution of visual pollen signals. Plant Syst. Evol. 222, 89-111 (2000).

35. Nicholls, E. \& Hempel de Ibarra, N. Assessment of pollen rewards by foraging bees. Funct. Ecol. 31, 76-87 (2017).

36. Tang, L.-L. \& Huang, S.-Q. Evidence for reductions in floral attractants with increased selfing rates in two heterandrous species. New Phytol. https://doi.org/10.1111/j.1469-8137.2007.02115.x (2007).

37. Faegri, K. \& Van Der Pijl, L. Principles of Pollination Ecology (Elsevier, 2013).

38. Dellinger, A. S. Pollination syndromes in the 21st century: where do we stand and where may we go?. New Phytol. https://doi.org/ 10.1111/nph.16793 (2020).

39. Kostyun, J. L., Gibson, M. J. S., King, C. M. \& Moyle, L. C. A simple genetic architecture and low constraint allow rapid floral evolution in a diverse and recently radiating plant genus. New Phytol. 223, 1009-1022 (2019).

40. Roguz, K. et al. Diversity of nectar amino acids in the Fritillaria (Liliaceae) genus: ecological and evolutionary implications. Sci. Rep. 9, 1-12 (2019).

41. Roguz, K. et al. Functional diversity of nectary structure and nectar composition in the genus Fritillaria (liliaceae). Front. Plant Sci. 9, 1-21 (2018).

42. Zych, M. \& Stpiczyńska, M. Neither protogynous nor obligatory out-crossed: Pollination biology and breeding system of the European Red List Fritillaria meleagris L. (Liliaceae). Plant Biol. 14, 285-294 (2012).

43. Day, P. D. et al. Evolutionary relationships in the medicinally important genus Fritillaria L. (Liliaceae). Mol. Phylogenet. Evol. 80, 11-19 (2014).

44. Hayashi, K. Molecular systematics of Lilium and allied genera (Liliaceae): phylogenetic relationships among Lilium and related genera based on the rbcL and matK gene sequence data. Plant Species Biol. 15, 73-93 (2000).

45. Stpiczyńska, M., Nepi, M. \& Zych, M. Nectaries and male-biased nectar production in protandrous flowers of a perennial umbellifer Angelica sylvestris L. (Apiaceae). Plant Syst. Evol. https://doi.org/10.1007/s00606-014-1152-3 (2014).

46. Hill, L. A taxonomic history of Japanese endemic Fritillaria (Liliaceae). Kew Bull. 66, 227-240 (2018).

47. Kiani, M. et al. Iran supports a great share of biodiversity and floristic endemism for Fritillaria spp. (Liliaceae): a review. Plant Divers. 39, 245-262 (2017)

48. Shaw, A. J. Phylogeny of the Sphgnpsida based on chloroplast and nuclear DNA sequences. Bryologist 103, 277-306 (2000).

49. Rønsted, N., Law, S., Thornton, H., Fay, M. F. \& Chase, M. W. Molecular phylogenetic evidence for the monophyly of Fritillaria and Lilium (Liliaceae; Liliales) and the infrageneric classification of Fritillaria. Mol. Phylogenet. Evol. 35, 509-527 (2005).

50. Tekşen, M. \& Aytaç, Z. The revision of the genus Fritillaria L. (Liliaceae) in the Mediterranean region (Turkey). Turk. J. Bot. 35 , $447-478$ (2011).

51. Roguz, K., Hill, L., Roguz, A. \& Zych, M. Evolution of bird and insect flower traits in Fritillaria L. (Liliaceae). Front. Plant Sci. 12, $656783(2020)$

52. Zaharof, E. Variation and taxonomy of Fritillaria graeca (Liliaceae) in Greece. Plant Syst. Evol. 154, 41-61 (1986).

53. Búrquez, A. \& Burquez, A. Blue tits, Parus caeruleus, as pollinators of the crown imperial, Fritillaria imperialis, in Britain. Oikos 55, 335 (1989).

54. Peters, W. S., Pirl, M., Gottsberger, G. \& Peters, D. Pollination of the crown imperial Fritillaria imperialis by great tits Parus major. J. Ornithol. 136, 207-212 (1995).

55. Pendegrass, K. \& Robinson, A. A recovery plan for Fritillaria gentneri (Gentner's fritillary). Agric. U.S.F.a.W. Serv. (2005).

56. Zox, H. Ecology of black lily (Fritillaria camschatcensis): a Washington State sensitive species. Douglasia (2008).

57. Cronk, Q. \& Ojeda, I. Bird-pollinated flowers in an evolutionary and molecular context. J. Exp. Bot. 59, 715-727 (2008).

58. Lunau, K. \& Verhoeven, C. Wie Bienen Blumen sehen: Falschfarbenaufnahmen von Blüten. Biol. Unserer Zeit 47, 120-127 (2017).

59. Kranas, H., Spalik, K. \& Banasiak, Ł. MatPhylobi, 0.1 (University of Warsaw, 2018).

60. Kuraku, S., Zmasek, C. M., Nishimura, O. \& Katoh, K. Leaves facilitates on-demand exploration of metazoan gene family trees on MAFFT sequence alignment server with enhanced interactivity. Nucleic Acids Res. https://doi.org/10.1093/nar/gkt389 (2013).

61. Maddison, W. P. \& Maddison, D. R. Mesquite: a modular system for evolutionary analysis. Evolution 62, 1103-1118 (2018).

62. Stamatakis, A. RAxML version 8: a tool for phylogenetic analysis and post-analysis of large phylogenies. Bioinform. Appl. 30, 1312-1313 (2014).

63. Suchard, M. A. et al. Bayesian phylogenetic and phylodynamic data integration using BEAST 1.10. Virus Evol. https://doi.org/10. 1093/ve/vey016 (2018).

64. Kim, J. S. \& Kim, J. H. Updated molecular phylogenetic analysis, dating and biogeographical history of the lily family (Liliaceae: Liliales). Bot. J. Linn. Soc. 187, 579-593 (2018).

65. Cockerell, T. D. A. Two new plants from the tertiary rocks of the west. Torrey Bot. Soc. 14, 135-137 (1914).

66. Ettingshausen, C. B. III. 'Report on Phyto-Palaeontologieal Investigations of Fossil Flora of Alum Bay.'By Dr. (1AD).

67. Conran, J. G., Carpenter, R. J. \& Jordan, G. J. Early Eocene Ripogonum (Liliales: Ripogonaceae) leaf macrofossils from southern Australia. Aust. Syst. Bot. 22, 219-228 (2009).

68. Lanfear, R., Calcott, B., Ho, S. Y. W. \& Guindon, S. PartitionFinder: combined selection of partitioning schemes and substitution models for phylogenetic analyses. Mol. Biol. Evol. https://doi.org/10.1093/molbev/mss020 (2012).

69. Paradis, E. \& Schliep, K. Phylogenetics ape 5.0: an environment for modern phylogenetics and evolutionary analyses in R. Bioinformatics https://doi.org/10.1093/bioinformatics/bty633 (2019).

70. Revell, L. J. phytools: an R package for phylogenetic comparative biology (and other things). Methods Ecol. Evol. 3, 217-223 (2012).

71. Garland, T., Dickerman, A. W., Janis, C. M. \& Jones, J. A. Phylogenetic Analysis of Covariance by Computer Simulation. vol. 42, 1993. https://academic.oup.com/sysbio/article/42/3/265/1629506 (Accessed 09 March 2021). 
72. Orme, C. D. L. The caper package: comparative analyses in phylogenetics and evolution in R, 1-36, 2012. See http://caper.r-forge.rproject.org/. (Accessed 09 March 2021).

73. TEAM, R. C. R: A Language and Environment for Statistical Computing (R Foundation for Statistical Computing, 2018).

74. Dyer, A. G. et al. Parallel evolution of angiosperm colour signals: common evolutionary pressures linked to hymenopteran vision. Proc. R. Soc. B Biol. Sci. 279, 3606-3615 (2012).

75. Ollerton, J. Reconciling ecological processes with phylogenetic patterns: the apparent paradox of plant-pollinator systems. J. Ecol. 84, 767-769 (1996).

76. Wessinger, C. A. \& Rausher, M. D. Predictability and irreversibility of genetic changes associated with flower color evolution in Penstemon barbatus. Evolution (N. Y.) 68, 1058-1070 (2014).

77. Wittmann, D., Radtke, R., Cure, J. R. \& Schifino-Wittmann, M. T. Coevolved reproductive strategies in the oligolectic bee Callonychium petuniae (Apoidea, Andrenidae) and three purple flowered Petunia species (Solanaceae) in southern Brazil. J. Zool. Syst. Evol. Res. 28, 157-165 (1990).

78. Chittka, L. \& Waser, N. M. Why red flowers are not invisible to bees. Isr. J. Plant Sci. 45, 169-183 (1997).

79. Kołodziejska-Degórska, I. \& Zych, M. Bees substitute birds in pollination of ornitogamous climber Campsis radicans (L.) seem. in Poland. Acta Soc. Bot. Pol. 75, 79-85 (2006).

80. Mayr, G. New specimens of the early oligocene old world hummingbird Eurotrochilus inexpectatus. J. Ornithol. 148, 105-111 (2007).

81. Mayr, G. Old world fossil record of modern-type hummingbirds. Science (80-.) 304, 861-864 (2004).

82. Schiestl, F. P. \& Johnson, S. D. Pollinator-mediated evolution of floral signals. Trends Ecol. Evol. 28, 307-315 (2013).

83. Daumer, K. Blumenfarben, wie sie die Bienen sehen. Z. Vgl. Physiol. 41, 49-110 (1958).

84. Kevan, P. G. Floral colours in the high Arctic with reference to insect flower relations and pollination. Can. J. Bot. 50, 2289-2316 (1972).

85. Chittka, L., Shmida, A., Troje, N. \& Menzel, R. Ultraviolet as a component of flower reflections, and the colour perception of hymenoptera. Vis. Res. 34, 1489-1508 (1994).

86. Lunau, K. Stamens and mimic stamens as components of floral colour patterns. Bot. Jahrbücher für Syst. Pflanzengeschichte und Pflanzengeographie 127, 13-41 (2006).

87. Koski, M. H. \& Ashman, T. L. Dissecting pollinator responses to a ubiquitous ultraviolet floral pattern in the wild. Funct. Ecol. 28, 868-877 (2014).

88. Menzel, R. \& Shmida, A. The ecology of flower colours and the natural colour vision of insect pollinators: the Israeli flora as a study case. Biol. Rev. 68, 81-120 (1993).

89. van der Kooi, C. J. \& Stavenga, D. G. Vividly coloured poppy flowers due to dense pigmentation and strong scattering in thin petals. J. Comp. Physiol. A Neuroethol. Sens. Neural Behav. Physiol. 205, 363-372 (2019).

90. Kevan, P., Giurfa, M. \& Chittka, L. Why are there so many and so few white flowers?. Trends Plant Sci. 1, 280-284 (1996).

91. Kapustjansky, A., Chittka, L. \& Spaethe, J. Bees use three-dimensional information to improve target detection. Naturwissenschaften 97, 229-233 (2010).

92. Chittka, L. \& Raine, N. E. Recognition of flowers by pollinators. Curr. Opin. Plant Biol. 9, 428-435 (2006).

93. Hansen, D. M., Olesen, J. M., Mione, T., Johnson, S. D. \& Müller, C. B. Coloured nectar: Distribution, ecology, and evolution of an enigmatic floral trait. Biol. Rev. 82, 83-111 (2007).

94. Raguso, R. A. Start making scents: the challenge of integrating chemistry into pollination ecology. Entomol. Exp. Appl. 128, 196-207 (2008).

95. Sapir, Y., Shmida, A. \& Ne'eman, G. Morning floral heat as a reward to the pollinators of the Oncocyclus irises. Oecologia 147, 53-59 (2006).

96. Bazzaz, F. A. \& Carslon, R. W. Photosynthetic contribution of flowers and seeds to reproductive effort of an annual colonizer. New Phytol. 82, 223-232 (1979).

\section{Acknowledgements}

Special thanks to Krysia Jędrzejewska-Szmek for help with the Photoshop analysis. We thank Dorota Szubierajska for helping to maintain experimental plants; Paul Cumbleton, Colin Everett, Paweł Kalinowski and U.S. Fish and Wildlife Service for providing plant material; Christian Verhoeven for consulting false colour pictures; Michał Chyliński for help with spectral analysis. The study was financially supported by research Grant No. 4786 2013/11/N/NZ8/00611 from the Polish National Science Centre (to KR).

\section{Author contributions}

K.R. and M.Z. conceived the study; K.R., K.L. and L.H. assembled field data; K.R., S.K., K.L. performed nectar analysis, K.R., S.K., K.L., M.Z. analyzed the data; S.K., L.H. and K.R. assembled photographic documentation; K.R. and M.Z. with support from K.L. and S.K. wrote the draft version of the paper. L.H. corrected the manuscript. All authors contributed to the final version.

\section{Competing interests}

The authors declare no competing interests.

\section{Additional information}

Supplementary Information The online version contains supplementary material available at https://doi.org/ 10.1038/s41598-021-90140-7.

Correspondence and requests for materials should be addressed to K.R.

Reprints and permissions information is available at www.nature.com/reprints.

Publisher's note Springer Nature remains neutral with regard to jurisdictional claims in published maps and institutional affiliations. 
(c) (i) Open Access This article is licensed under a Creative Commons Attribution 4.0 International cc) License, which permits use, sharing, adaptation, distribution and reproduction in any medium or format, as long as you give appropriate credit to the original author(s) and the source, provide a link to the Creative Commons licence, and indicate if changes were made. The images or other third party material in this article are included in the article's Creative Commons licence, unless indicated otherwise in a credit line to the material. If material is not included in the article's Creative Commons licence and your intended use is not permitted by statutory regulation or exceeds the permitted use, you will need to obtain permission directly from the copyright holder. To view a copy of this licence, visit http://creativecommons.org/licenses/by/4.0/.

(C) The Author(s) 2021 